\title{
Hepatoprotective activity of polyhydroxylated 2-styrylchromones against tert-butylhydroperoxide induced toxicity in freshly isolated rat hepatocytes
}

\author{
Eduarda Fernandes · Márcia Carvalho \\ Félix Carvalho $\cdot$ Artur M. S. Silva \\ Clementina M. M. Santos · Diana C. G. A. Pinto \\ José A. S. Cavaleiro · Maria de Lourdes Bastos
}

\begin{abstract}
Styrylchromones are a novel class of chromones, vinylogues of flavones (2-phenylchromones), which have recently been found in nature. The best described property of almost every group of flavones and other flavonoids, especially the hydroxylated derivatives, is their capacity to act as antioxidants. Indeed there is a widely accepted view that the positive health effects of flavones are due to their antioxidant activity. As oxidative stress is a main cause of liver toxicity induced by several hepatotoxicants, agents with the ability to protect the liver against reactive pro-oxidant species may be therapeutically useful. The present study evaluated the possible protective activity of six new synthetic polyhydroxylated 2-styrylchromone derivatives against the pro-oxidant hepatotoxicity exerted by tert-butylhydroperoxide ( $t$-BHP) in freshly isolated rat hepatocytes. The cells were preincubated with the 2-styrylchromones in the final concentrations of $3.125,12.5,25,50,100$, and $200 \mu \mathrm{M}$ for $5 \mathrm{~min}$ before treatment with $1.0 \mathrm{mM} t$-BHP for $30 \mathrm{~min}$ (throughout this incubation period the cells were exposed to both compounds). The well-known antioxidant 3-hydroxyflavone (quercetin) was used as positive control. At the end of the 30-min incubation period, aliquots of cells suspensions were taken for measurement of lactate dehydrogenase leakage,
\end{abstract}

E. Fernandes $(\varangle) \cdot$ M. Carvalho $\cdot$ F. Carvalho M. de Lourdes Bastos

REQUIMTE, Toxicology Department, Faculty of Pharmacy, University of Porto, Rua Anibal Cunha 164, 4050-047, Porto, Portugal

E-mail: egracas@ff.up.pt

Fax: + 351-222003977

A. M. S. Silva · C. M. M. Santos - D. C. G. A. Pinto

J. A. S. Cavaleiro

Department of Chemistry, University of Aveiro, 3810-193

Aveiro, Portugal

Present address: E. Fernandes

REQUIMTE, Physical-Chemistry Department,

Faculty of Pharmacy, University of Porto,

Rua Aníbal Cunha 164, 4050-047, Porto, Portugal thiobarbituric acid reactive substances, reduced glutathione, and oxidized glutathione contents. The tested compounds exhibited in vitro protective activity against $t$-BHP induced hepatotoxicity $(1.0 \mathrm{mM}, 30 \mathrm{~min})$. Three of the tested compounds, at the concentrations of 3.125, $12.5,25$, and $50 \mu \mathrm{M}$, prevented the $t$-BHP induced glutathione depletion, lipid peroxidation, and cell death in freshly isolated rat hepatocytes to a comparable potency with that of quercetin.

Keywords 2-Styrylchromones $\cdot$ tertButylhydroperoxide $\cdot$ Hepatoprotective activity $\cdot$ Freshly isolated rat hepatocytes

\section{Introduction}

2-Styrylchromones are a novel class of chromones, vinylogues of flavones (2-phenylchromones), which have recently been found in nature, specifically the compounds hormothamnione and 6-desmethoxyhormothamnione in the marine blue-green algae Chrysophaem taylori (Gerwick 1989; Gerwick et al. 1986). Before and after the isolation of natural 2-styrylchromones several analogues of these compounds have been synthesized and tested in different biological systems. The natural derivatives demonstrated cytotoxic activity against leukemia cells (Gerwick 1989; Gerwick et al. 1986), and those obtained by synthesis exhibited antiallergic (Doria et al. 1979), antiviral (Desideri et al. 2000), antitumor (Brion et al. 1991), antagonism of $A_{3}$ adenosine receptor (Karton et al. 1996), and xanthine oxidase inhibitor (Fernandes et al. 2002) properties. Notwithstanding, the best described property of almost every group of flavones and other flavonoids, especially of the hydroxylated derivatives, is their capacity to act as antioxidants. Indeed it is widely accepted that the positive health effects of flavonoids is due to their antioxidant activity (Nijveldt et al. 2001). Since oxidative stress 
is a main cause of liver toxicity induced by several hepatotoxicants, agents with the ability to protect the liver against reactive pro-oxidant species may be therapeutically useful. This is true for several polyhydroxylated flavonoids which have already been shown to be hepatoprotective, as is the case of kolaviron (a mixture of Garcinia biflavonoids; Farombi et al. 2000), catechins (Kagaya et al. 2002), quercetin (Gilani et al. 1997), tilosiride (Matsuda et al. 2002), and morin (Wu et al. 1993). Therefore, although such an effect could be expected from polyhydroxylated 2-styrylchromones, it has yet to be experimentally demonstrated. Thus the aim of the present study was to evaluate the possible protective activity of six synthetic polyhydroxylated 2-styrylchromones (Fig. 1) against the tert-butylhydroperoxide $(t$-BHP) induced pro-oxidant hepatotoxicity in freshly isolated rat hepatocytes. Quercetin (Fig. 1) was tested in the same experimental conditions as positive control.

\section{Materials and methods}

\section{Chemicals}

All reagents were of analytical grade. The following reagents were obtained from Sigma (St. Louis, Mo., USA): collagenase (grade IV), $t$-BHP, bovine serum albumin, hydroxyethylpiperazine ethanesulfonic acid (HEPES), reduced glutathione (GSH), oxidized glutathione (GSSG), glutathione reductase (EC 1.6.4.2), 5,5'-dithio-bis-(2-nitrobenzoic acid) (DTNB), $\beta$-nicotinamide adenine dinucleotide phosphate reduced form ( $\beta$-NADPH), $\beta$-nicotinamide adenine dinucleotide reduced form $(\beta$-NADH), quercetin, 2-thiobarbituric acid (TBA), and 2-vinylpyridine.

The 2-styrylchromones tested in the present study were synthesized from 2'-hydroxyacetophenones and cinnamic acid derivatives (Pinto et al. 1998, 2000).<smiles>[R]c1cc(Br)c2c(=O)cc(/C=C/c3ccc(O)c(O)c3)oc2c1</smiles>

Styrylchromone 1a): $\mathrm{R} 1=\mathrm{OH} \quad \mathrm{R} 2=\mathrm{H}$ Styrylchromone 1b): $\mathrm{R} 1=\mathrm{H} \quad \mathrm{R} 2=\mathrm{OH}$ Styrylchromone 1c): $\mathrm{R} 1=\mathrm{R} 2=\mathrm{OH}$<smiles>[R9]c1cc([18OH])c2c(=O)cc(/C=C/c3ccc(O)cc3)oc2c1</smiles>
Styrylchromone 2a): $\mathbf{R} 1=\mathrm{OH}, \quad \mathrm{R} 2=\mathrm{H}$ Styrylchromone 2b): R1 = H, R2 = OH Styrylchromone 2c): R1 = R2 $=\mathrm{OH}$<smiles>O=c1c(O)c(-c2ccc(O)c(O)c2)oc2cc(O)cc(O)c12</smiles>

Quercetin

Fig. 1 Chemical structures of the tested 2-styrylchromones and of quercetin
Animals

Housing and experimental treatment of the mice were conducted under the European Community guidelines for the use of experimental animals (European Convention for the Protection of Vertebrate Animals Used for Experimental and Other Scientific Purposes, 1986, and Protocol of Amendment to the European Convention for the Protection of Vertebrate Animals Used for Experimental and Other Scientific Purposes, 1998). Adult male Wistar rats weighing 200-250 g were used. The rats were kept in polyethylene cages lined with wood shavings with wire mesh at the top and acclimatized at $20 \pm 2^{\circ} \mathrm{C}$, humidity $40-60 \%$, and $12 / 12 \mathrm{~h}$ light/dark cycle. The animals had free access to standard rat chow and tap drinking water, and were kept in our facilities for at least 2 weeks prior to use. Surgical procedures for the isolation of hepatocytes were performed under anesthesia and carried out between 10 a.m. and 11 a.m.

\section{Isolation of hepatocytes}

The isolation of hepatocytes was performed by collagenase perfusion as previously described (Fernandes et al. 1995). The initial viability of the isolated hepatocytes was always higher than $85 \%$, as estimated by the trypan blue exclusion method. Incubations were performed at $37^{\circ} \mathrm{C}$ in suspensions of $10^{6}$ viable cells per milliliter in $12.5 \mathrm{mM}$ Krebs-Henseleit-HEPES buffer $(\mathrm{pH} 7.4)$ and aerated with a stream of carbogen $\left(95 \% \mathrm{O}_{2}\right.$ and $\left.5 \% \mathrm{CO}_{2}\right)$. The hepatocytes were always preincubated for $60 \mathrm{~min}$ at $37^{\circ} \mathrm{C}$ before the beginning of the experiments.

\section{Studies of hepatoprotection}

The cells were preincubated with $10 \mu \mathrm{l} / \mathrm{ml}$ of the studied 2-styrylchromones dissolved in DMSO in the final concentrations of $3.125,12.5,25$, and $50 \mu \mathrm{M}$ for compounds $1 \mathrm{a}, 1 \mathrm{~b}$, and $1 \mathrm{c}$ (bearing a catechol group in the styryl moiety), and $25,50,100$, and $200 \mu \mathrm{M}$ for compounds $2 \mathrm{a}, 2 \mathrm{~b}$, and $2 \mathrm{c}$ (bearing a phenol group in the styryl moiety: Fig. 1) for $5 \mathrm{~min}$ before treatment with $1.0 \mathrm{mM} t$-BHP for 30 min (throughout this incubation period the cells are exposed to both components). The well-known antioxidant quercetin was used as positive control in these experiments. The cells were preincubated with $10 \mu \mathrm{l} / \mathrm{ml}$ quercetin dissolved in DMSO at the same final concentrations for $5 \mathrm{~min}$ before treatment with $1.0 \mathrm{mM} t$-BHP for $30 \mathrm{~min}$. At the end of the experiments aliquots of cells suspensions were taken for measurement of lactate dehydrogenase (LDH) leakage, thiobarbituric acid reactive substances (TBARS) and reduced glutathione (GSH) and oxidized glutathione (GSSG) contents.

\section{Analytical procedures}

Cell death was determined spectrophotometrically by quantification of LDH activity in the incubation medium vs. total LDH activity in the cells homogenate. The results are shown as percentages of control cell viability.

The extent of cellular lipid peroxidation was determined indirectly by the malondialdehyde formation after the breakdown of polyunsaturated fatty acids, as described previously (Fernandes et al. 1995). Briefly, $250 \mu \mathrm{l}$ aliquots of cell suspensions were precipitated with $500 \mu \mathrm{l}$ of $10 \%$ trichloroacetic acid and centrifuged for $20 \mathrm{~s}$ at $6000 \mathrm{rpm}$. We added $500 \mu \mathrm{l}$ of the supernatant with an equal volume of $1 \%$ thiobarbituric acid, and the mixture was heated during $10 \mathrm{~min}$ in a boiling water bath and allowed to cool, being the absorbance measured at $535 \mathrm{~nm}$.

The glutathione content of cell suspensions was determined by the DTNB-GSSG reductase recycling assay as described previously (Anderson 1985) with some modifications. Briefly, $200 \mu \mathrm{l}$ of cell suspension were added to $200 \mu \mathrm{l}$ of $10 \%(\mathrm{w} / \mathrm{v})$ perchloric acid for 
protein precipitation and centrifuged for $10 \mathrm{~min}$ at $13000 \mathrm{rpm}$, $4^{\circ} \mathrm{C}$. Perchloric acid was then neutralized with an equimolar concentration of $\mathrm{KHCO}_{3}$, and a new centrifugation was performed for $1 \mathrm{~min}$ at $13,000 \mathrm{rpm}, 4^{\circ} \mathrm{C}$. Supernatant aliquots were taken for measurement of total glutathione following the DTNB reduction at $415 \mathrm{~nm}$ and compared with a standard curve. The final concentrations in the assay were $0.6 \mathrm{mM}$ DTNB, $0.21 \mathrm{mM} \mathrm{NADPH}$, and $2 \mathrm{U} / \mathrm{ml}$ GSSG reductase. For the GSSG determination $100 \mu \mathrm{l}$ acidic supernatant aliquots were treated with $5 \mu$ l 2-vinylpyridine and mixed continuously for $60 \mathrm{~min}$ for derivatization of GSH. GSSG was then measured as described above for total glutathione. The GSH levels were calculated by subtracting GSSG content from the total glutathione content. Of note, none of the studied compounds interfered with this assay when assayed with standards (data not shown).

Statistical analysis

Data are expressed as mean $\pm \operatorname{SEM}(n=4$ or 5 ; cells obtained from four or five rats). Significant differences between $t$-BHP treated cells and $t$-BHP plus hepatoprotective compound treated cells were determined by one-way analysis of variance followed by Fisher's probabilistic least significant difference test. Differences were considered significant with $P$ values at or less than 0.05 .

\section{Results}

Figures 2 and 3 show GSH and GSSG levels, lipid peroxidation, and the viability of isolated hepatocytes in control conditions after $t$-BHP induced alone-treatment $(1.0 \mathrm{mM}, 30 \mathrm{~min})$ and after pretreatment with 2 -styrylchromones $1 \mathrm{a}, 1 \mathrm{~b}$, and $1 \mathrm{c}$ or quercetin and treatment with $t$-BHP. The results obtained for the same biological parameters from the studies with the tested 2-styrylchromones $2 \mathrm{a}, 2 \mathrm{~b}$, and $2 \mathrm{c}$ are presented in Figs. 4 and 5. As expected, incubation of the cells with $t$-BHP resulted in a significant depletion of GSH, GSSG formation, and increase in lipid peroxidation, with a consequent significant decrease in cell viability (Figs. 2, 3, 4, 5).

The results obtained with the 2-styrylchromones 1a, $1 \mathrm{~b}$, and $1 \mathrm{c}$ clearly show that these compounds exhibit in vitro protective activity against $t$-BHP-induced hepatotoxicity. In the studied concentrations $(3.125,12.5,25$, and $50 \mu \mathrm{M})$ these compounds prevented $t$-BHP-induced glutathione depletion and GSSG formation (Fig. 2) as well as lipid peroxidation and cell death (Fig. 3) in freshly isolated rat hepatocytes, in a concentrationdependent manner, with a similar potency among them and also comparable with that of quercetin. Of note, the prevention attained for cell viability and lipid peroxidation was virtually complete for the highest concentration tested $(50 \mu \mathrm{M})$ (Fig. 3) while the protection against GSH depletion and GSSG formation was not complete (Fig. 2).

The results obtained with the 2-styrylchromones $2 \mathrm{a}$, $2 \mathrm{~b}$, and $2 \mathrm{c}$ demonstrate that its in vitro protective activity against $t$-BHP induced hepatotoxicity is much lower than that of the catechol derivatives. In fact, in order to achieve protection the tested concentrations had to increase substantially $(25,50,100$, and $200 \mu \mathrm{M})$. Nevertheless, it was also observed a concentration-
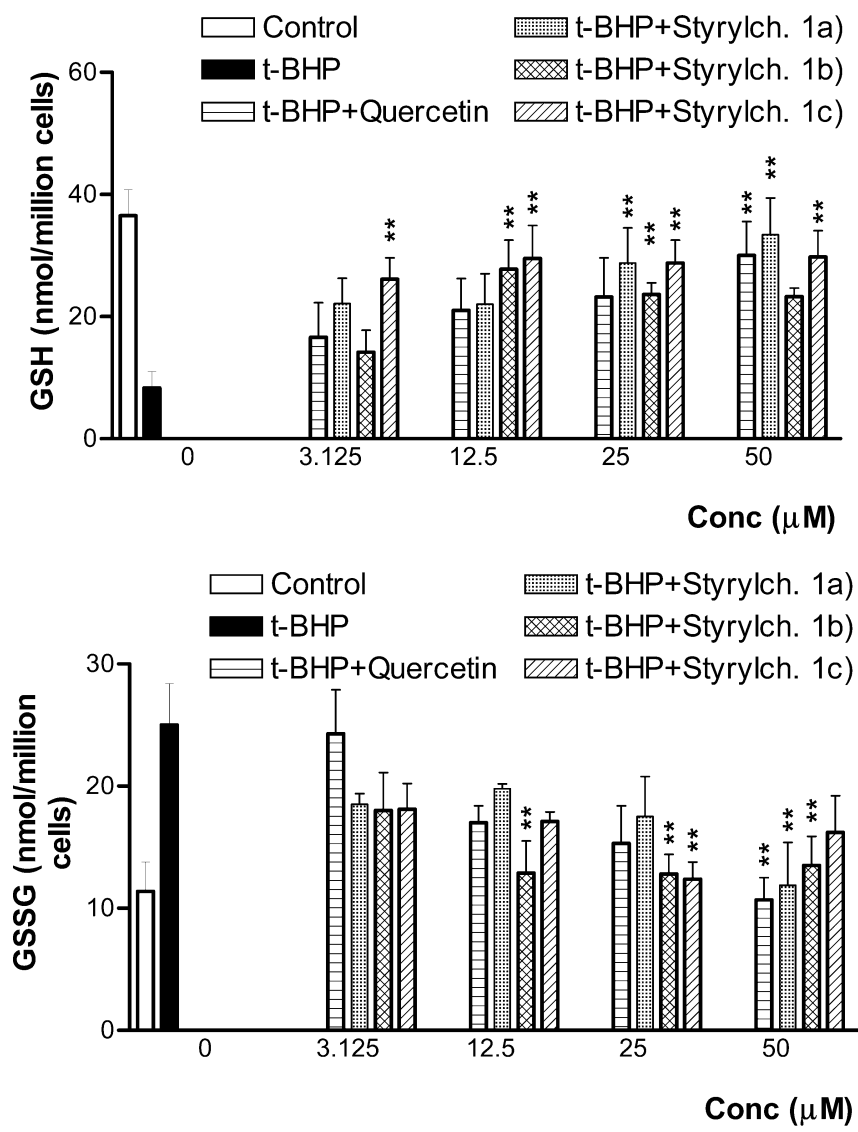

Fig. 2 Effect of pretreatment with 2-styrylchromones 1a, 1b, and $1 \mathrm{c}$, and quercetin on reduced and oxidized glutathione (GSH and GSSG) of hepatocyte suspensions treated with $t$-BHP $(1.0 \mathrm{mM})$ for 30 min (mean \pm SEM), $n=4$ or 5 . ${ }^{* *} P<0.01$ vs. cells treated only with $t$-BHP

dependent prevention of $t$-BHP induced loss of cell viability and $t$-BHP induced increase in lipid peroxidation (Fig. 5), whose levels almost reached the control values at the highest concentration tested. Again, no clearcut difference was observed in what concerns to the potency among $2 \mathrm{a}, 2 \mathrm{~b}$, and 2c 2-styrylchromones. Interestingly, these three compounds were devoid of a protective effect against $t$-BHP-induced depletion of GSH and formation of GSSG (Fig. 4) for any of the tested concentrations, although a non-concentrationdependent protective trend was noted.

\section{Discussion}

The use of $t$-BHP has been generally accepted to induce oxidative damage to isolated hepatocytes in studies of hepatoprotection. $t$-BHP is metabolized to tert-butyl alcohol by glutathione peroxidase, in isolated rat hepatocytes, with consumption of GSH and production of GSSG (Sies and Summer 1975). Under severe exposure to $t$-BHP the reduction of GSSG by glutathione reductase or the regeneration of NADPH may be insufficient, which results in the accumulation and export of GSSG 

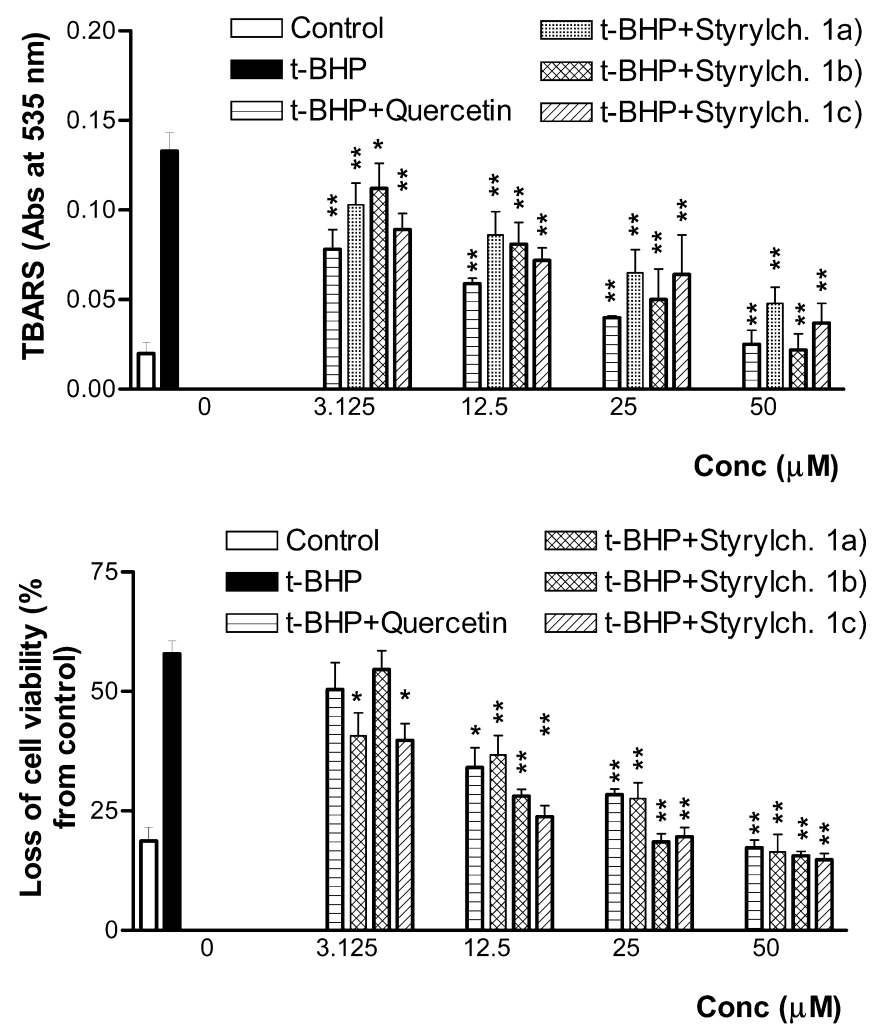

Fig. 3 Effect of pretreatment with 2-styrylchromones 1a, 1b, and 1c and quercetin on cell viability (measured by proportion of $\mathrm{LDH}$ leakage) and lipid peroxidation (TBARS production) of hepatocyte suspensions treated with $t$-BHP $(1.0 \mathrm{mM})$ for $30 \mathrm{~min}$ (mean \pm SEM), $n=4$ or 5 . ${ }^{*} P<0.05,{ }^{*} P<0.01$ vs. cells treated only with $t$-BHP

from the cells. A dramatic depletion of intracellular GSH may increase cellular susceptibility to irreversible injury by oxidative stress, namely by free radicals. Another characteristic of $t$-BHP-induced hepatotoxicity is the metabolic formation of the corresponding peroxyl and alkoxyl radicals catalyzed by the cytochrome P-450 system (Cadenas and Sies 1982). These are the oxygen reactive species implicated in the initiation and propagation of lipid peroxidation as well as in glutathione oxidation (Bellomo et al. 1982; Fernandes et al. 1995; Jewell et al. 1986; Rush et al. 1985). $t$-BHP-induced alkylation of cellular macromolecules or oxidation of thiol groups in cellular proteins has also been reported (Farghali et al. 2000). These events are followed by formation of surface blebs in the plasma membrane as well as the leakage of cytosolic enzymes in the incubation medium. In accordance with the mechanism of toxicity of $t$-BHP, it has been shown before that the deleterious effects of $t$-BHP can be prevented by antioxidants and free radical scavengers (Fernandes et al. 1995; Jewell et al. 1986; Joyeux et al. 1990).

The data reported here demonstrate that all studied 2-styrylchromones exhibit hepatoprotective activity against acute $t$-BHP toxicity in vitro. The protective effect of both groups of 2-styrylchromones was reflected on the preservation of the integrity of the plasma
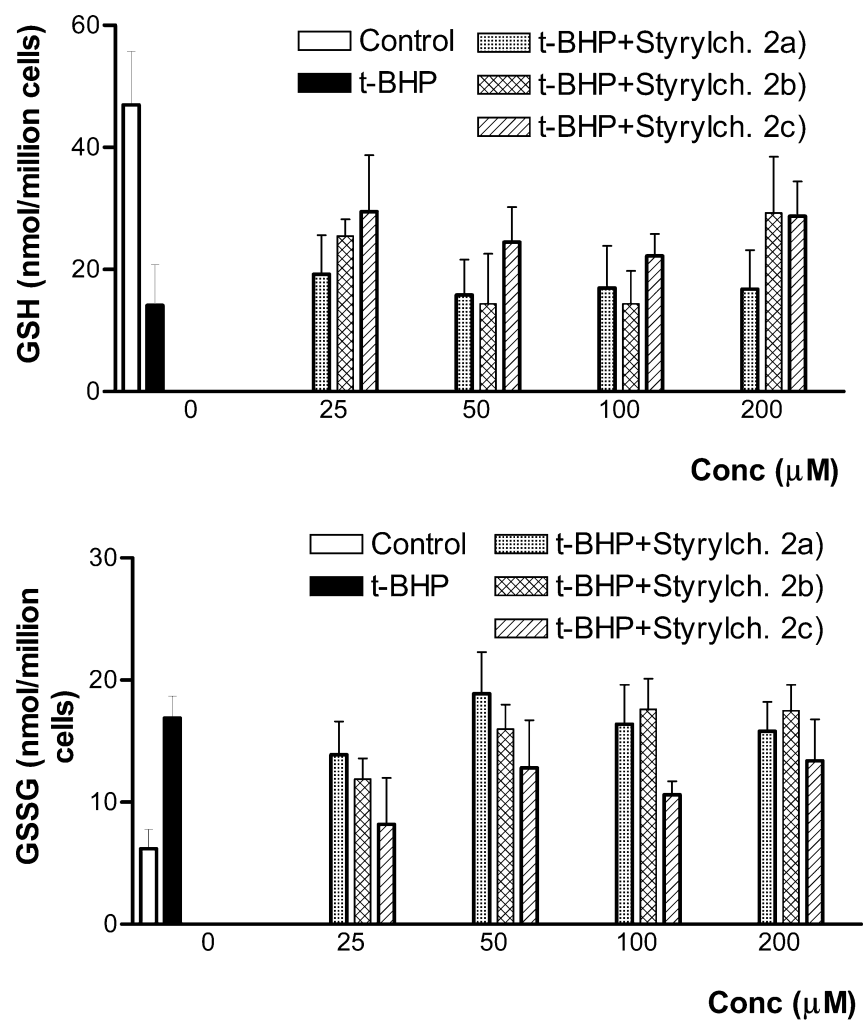

Fig. 4 Effect of pretreatment with 2-styrylchromones 2a, 2b, and 2c on reduced and oxidized glutathione (GSH and GSSG) of hepatocyte suspensions treated with $t$-BHP $(1.0 \mathrm{mM})$ for $30 \mathrm{~min}$ (mean \pm SEM), $n=4$ or 5

membrane. However, it was evident that the styrylcatechol-derivatives were much more potent than the styrylphenol derivatives. The differences between the two groups of compounds were also observed in what concerns the qualitative and quantitative preservation of biochemical homeostasis. In fact, while the hepatoprotective effect for 2-styrylchromones $1 \mathrm{a}, 1 \mathrm{~b}$, and $1 \mathrm{c}$ involves the prevention of lipid peroxidation and the inhibition of GSH depletion and of GSSG formation at concentrations ranging from 3.125 to $50 \mu \mathrm{M}$, the 2-styrylchomones $2 \mathrm{a}, 2 \mathrm{~b}$, and $2 \mathrm{c}$ only partially prevented lipid peroxidation, and had no effect on glutathione levels, at concentrations ranging from 25 to $200 \mu \mathrm{M}$.

Hepatic glutathione plays a central role in cellular detoxication of xenobiotics as well as of endogenous reactive intermediates. Rush et al. (1985) have shown that in isolated rat hepatocytes, depletion of intracellular GSH prior to $t$-BHP exposure results in greater lipid peroxidation and increased cell death than isolated rat hepatocytes without GSH depletion prior to $t$-BHP exposure. These authors also indicated that lipid peroxidation does not play a major role in $t$-BHP induced liver cell injury because no prevention of cell death occurred in isolated rat hepatocytes cotreated with $t$-BHP and the antioxidant promethazine, in spite of a complete blockade of lipid peroxidation. It has also been reported that in isolated rat hepatocytes the depletion of intracellular GSH by pretreatment with diethylmaleate 

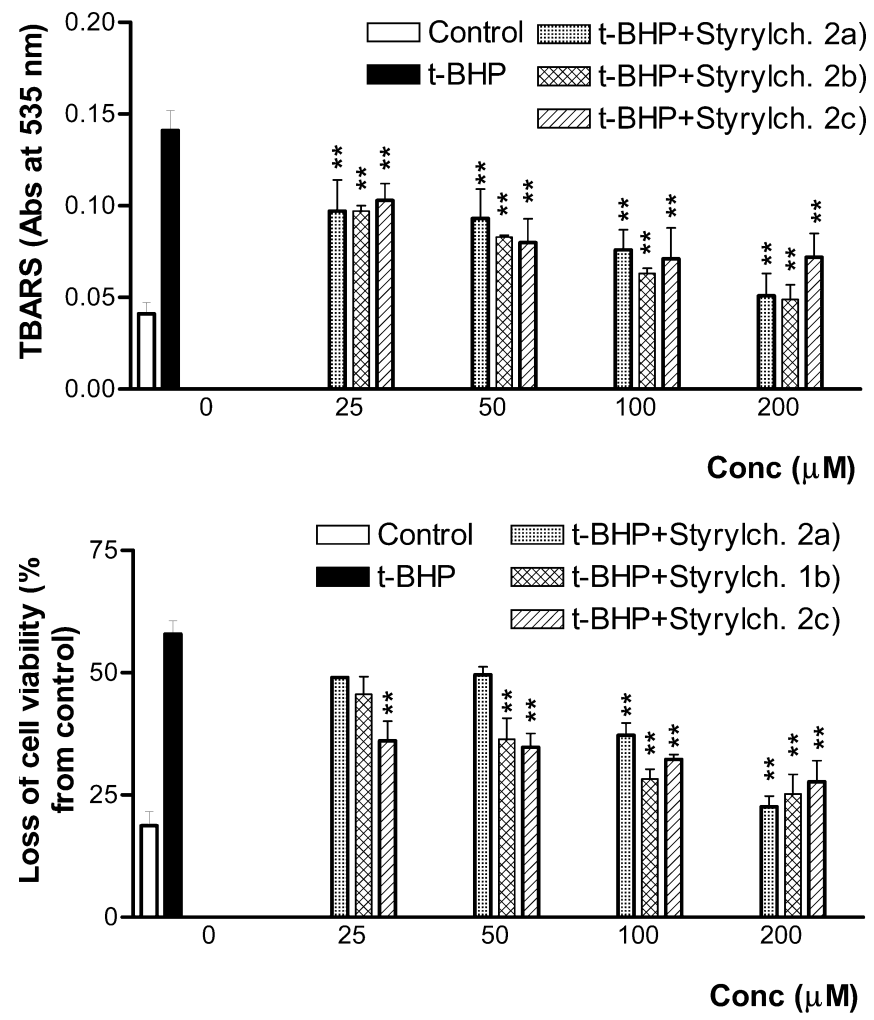

Fig. 5 Effect of pretreatment with 2-styrylchromones 2a, 2b, and 2c on cell viability (measured by proportion of LDH leakage) and lipid peroxidation (TBARS production) of hepatocyte suspensions treated with $t$-BHP $(1.0 \mathrm{mM})$ for 30 min (mean $\pm \mathrm{SEM}), n=4$ or 5 . $* * P<0.01$ vs. cells treated only with $t$-BHP

potentiates $t$-BHP induced cell toxicity with enhanced depletion of protein thiols even in the absence of lipid peroxidation (Jewell et al. 1986). In the present study the concomitant protective effect on glutathione levels, lipid peroxidation, and cell death obtained for low concentration of the styrylcatechol derivatives are in accordance with the importance of the preservation of high levels of endogenous GSH for the protection against $t$ BHP-induced cell injury. However, the protective effect obtained with the phenol derivatives indicates that the direct prevention of lipid peroxidation, on its own, also plays an important role in the final outcome. Noteworthy, it was already shown that an hepatoprotective effect against $t$-BHP induced lethality in isolated hepatocytes may be achieved by ruthenium red without affecting either glutathione depletion, lipid peroxidation, or adenosine triphosphate depletion (Groskreutz et al. 1992). It is possible that part of the protective effect elicited by the phenol derivatives may be due to the inhibition of cytochrome P-450, which would then decrease the formation of free radicals but increase the availability of $t$-BHP to be metabolized to tert-butyl alcohol by glutathione peroxidase leading to the formation of higher quantities of GSSG. However, this hypothesis was not further evaluated in the present study due to the fact that the styrylphenol derivatives were the less interesting in the viewpoint of the studied therapeutic effect.
The antioxidant properties (and thus protective propreties against pro-oxidant hepatotoxicants) of flavonoids have been attributed to their scavenging of lipid alkoxyl and peroxyl radicals through hydrogen donation, to the repair of oxidized proteins, to the regeneration of $\alpha$-tocopherol by $\alpha$-tocopheroxyl radical reduction, to their chelation potential of transition metal ions, and also to the inhibition of xanthine oxidase (Fernandes et al. 2002; Filipe et al. 2002; Nijveldt et al. 2001; Rice-Evans et al. 1996). The chemical structure of the compounds assayed in the present study is characterized by the presence of a benzopyrone moiety, which is a common feature of flavones with a $\mathrm{C}_{2}-\mathrm{C}_{3}$ double bond and a styrylcatechol or styrylphenol in $\mathrm{C}_{2}$ (Fig. 1). Structure-activity relationship studies of flavonoids have shown that the $o$-dihydroxy structure in the B ring and the 2,3 double bond in conjugation with the 4-oxo function in the $\mathrm{C}$ ring (as in flavones) are essential for effective free radical scavenging activity (Bors et al. 1990; Pannala and Rice-Evans 2001 and references therein). The presence of a 3-hydroxyl group in the heterocyclic ring also increases the radical-scavenging activity of flavonols, while additional hydroxyl groups at positions 5 and 7 of the A ring appear to be less important. These structural features contribute to increasing the stability of the aroxyl radical, i.e., the antioxidant capacity of the parent compound. Hence our results are in accordance with previous structureactivity relationship studies of flavonoids, although further studies with new modified styrylchromones need to be performed to clarify these relationships. Interestingly, although the styrylcatechol derivatives assayed in the present study lack the 3-hydroxyl group in the heterocyclic ring their activity was similar to that of quercetin, which has it in its structure. This indicates that the styryl moiety may further contribute for the stabilization of the aroxyl radical in the molecule. Nonetheless, the present results confirm that the hydroxyl groups at positions 5 and 7 of the A ring are of low importance for the antioxidant effect. Noteworthy, the styrylcatechol linked to the benzopyrone moiety is common to caffeic acid, also an antioxidant compound with a potent hepatoprotective activity (Pérez-Alvarez et al. 2001). However, in conflict with our findings, the 4-monohydroxyl derivative of caffeic acid prevented the alteration of almost all of the hepatic injury markers induced by another hepatotoxicant $\left(\mathrm{CCl}_{4}\right)$ administration, with a greater efficacy than caffeic acid itself (Pérez-Alvarez et al. 2001). This may be due to other effects, such as the inhibition of either cyclooxygenase or lipoxygenase (or both) activity (Pérez-Alvarez 1993). Of note, the three 2styrylchromones shown to be highly hepatoprotective in the present study have already been shown to be outstanding inhibitors of xanthine oxidase (Fernandes et al. 2002) and scavengers of superoxide radicals (Fernandes et al. unpublished observations) which increases the interest for the use of such compounds in diseases in which the overproduction of superoxide radicals plays an important role. 
In conclusion, the results obtained in this study show that the tested compounds exhibit in vitro protective activity against $t$-BHP-induced hepatotoxicity and may be considered as new excellent antioxidants and potential therapeutic agents against pro-oxidant hepatic injuries. After combination of all data, three 2-styrylchromones, $1 \mathrm{a}, 1 \mathrm{~b}$ and $1 \mathrm{c}$, may be selected as the most promising for further investigation.

\section{References}

Anderson ME (1985) Determination of glutathione and glutathione disulfide in biological samples. Methods Enzymol 113:548-555

Bellomo G, Jewell SA, Thor H, Orrenius S (1982) Regulation of intracellular calcium compartmentation: studies with isolated hepatocytes and $t$-butyl hydroperoxide. Proc Natl Acad Sci USA 79:6842-6846

Bors W, Heller W, Michel C, Saran M (1990) Flavonoids as antioxidants. Determination of radical scavenging efficiencies. Methods Enzymol 186:343-355

Brion D, Le Baut G, Zammatio F, Pierre A, Atassi G, Belachm L (1991) Preparation of 2-styryl-4-chromanones as anticancer agents. European patent application EP 454:587. Chem Abstr 116:106092k

Cadenas E, Sies H (1982) Low level chemiluminiscence of liver microsomal fractions initiated by tert-butyl-hydroperoxide. Relation to microsomal hemoproteins, oxygen dependence, and lipid peroxidation. Eur J Biochem 124:349-356

Desideri N, Conti C, Mastromarino P, Mastropaolo F (2000) Synthesis and anti-rhinovirus activity of 2-styrylchromones. Antiviral Chem Chemother 11:373-381

Doria G, Romeo C, Forgione A, Sberze P, Tibolla N (1979) Antiallergic agents. III. Substituted trans-2-ethenyl-4-oxo-4H-1benzopyran-6-carboxylic acids. Eur J Med Chem 14:347-351

Farghali H, Kamenikova L, Hynie S, Kmonickova E (2000) Silymarin effects on intracellular calcium and cytotoxicity: a study in perfused rat hepatocytes after oxidative stress injury. Pharmacol Res 41:231-237

Farombi EO, Tahnteng JG, Agboola AO, Nwankwo JO, Emerole GO (2000) Chemoprevention of 2-acetylaminofluorene induced hepatotoxicity and lipid peroxidation in rats by kolaviron-A Garcinia kola seed extract. Food Chem Toxicol 38:535-541

Fernandes ER, Carvalho F, Remiao F, Bastos ML, Pinto MM, Gottlieb OR (1995) Hepatoprotective activity of xanthones and xanthonolignoids against tert-butylhydroperoxide-induced toxicity in isolated rat hepatocytes-comparison with silybin. Pharm Res 12:1756-1760

Fernandes ER, Carvalho F, Silva AMS, Santos CMM, Pinto DCGA, Cavaleiro JAS, Bastos ML (2002) 2-Styrylchromones as novel inhibitors of xanthine oxidase. A structure-activity study. J Enzyme Inhib Med Chem 17:45-48

Filipe $\mathrm{P}$, Morlière $\mathrm{P}$, Patterson LK, Hug GL, Mazière JC, Mazière C, Freitas JP, Fernandes A, Santus R (2002) Mechanisms of flavonoid repair reactions with amino acid radicals in models of biological systems: a pulse radiolysis study in micelles and human serum albumin. Biochim Biophys Acta 1572:150-162

Gerwick WH (1989) 6-Desmethoxyhormothamnione, a new cytotoxic styrylchromone from the marine cryptophyte Chrysophaeum taylori. J Nat Prod 52:252-256
Gerwick WH, Lopez A, Van Dyune GD, Clardy J, Ortiz W, Baez A (1986) Hormothamnione, a novel cytotoxic styrylchromone from the marine cyanophyte Hormothamnion enteromorphoides grunow. Tetrahedron Lett 27:1979-1982

Gilani AH, Janbaz KH, Shah BH (1997) Quercetin exhibits hepatoprotective activity in rats. Biochem Soc Trans 25:S619

Groskreutz JL, Bronk SF, Gores GJ (1992) Ruthenium red delays the onset of cell death during oxidative stress of rat hepatocytes. Gastroenterology 102:1030-1038

Jewell A, Monte DD, Richelmi R, Bellomo G, Orrenius S (1986) tert-butyl hydroperoxide induced toxicity in isolated hepatocytes: contribution of thiol oxidation and lipid peroxidation. J Biochem Toxicol 1:13-22

Joyeux M, Rolland A, Fleurentin J, Mortier J, Dorfman, P (1990) tert-butyl hydroperoxide induced injury in isolated isolated rat hepatocytes: a model for studying antihepatotoxic drugs. Planta Med 56:171-174

Kagaya N, Tagawa Y, Nagashima H, Saijo R, Kawase M, Yagi K (2002) Suppression of cytotoxin-induced cell death in isolated hepatocytes by tea catechins. Eur J Pharmacol 450:231

Karton Y, Jiang J, Ji X, Olah ME, Stiles GL, Jacobson KA (1996) Synthesis and biological activities of flavonoids derivatives as A3 adenosine receptor antagonists. J Med Chem 39:2293-2301

Matsuda H, Ninomiya K, Shimodab H, Yoshikawaa M (2002) Hepatoprotective principles from the flowers of Tilia argentea (Linden): structure requirements of tiliroside and mechanisms of action. Bioorgan Med Chem 10:707-712

Nijveldt RJ, van Nood E, van Hoorn DEC, Boelens PG, van Norren K, and van Leeuwen PAM (2001) Flavonoids: a review of probable mechanisms of action and potential applications. Am J Clin Nutr 74:418-425

Pannala AS, Chan TS, O'Brien PJ, Rice-Evans CA (2001) Flavonoid B-ring chemistry and antioxidant activity: fast reaction kinetics. Biochem Biophys Res Commun 282:11611168

Pérez-Alvarez V, Bobadilla-Lugo RA, Muriel P, Favari L, Villanueva-Lopez C (1993) Effects of leukotriene synthesis inhibition on acute liver damage induced by carbon tetrachloride. Pharmacology 47:330-336

Pérez-Alvarez V, Bobadilla-Lugo RA, Muriel P (2001) Structurehepatoprotective activity relationship of 3:4-dihydroxycinnamic acid (caffeic acid) derivatives. J Appl Toxicol 21:527-531

Pinto DCGA, Silva AMS, Almeida LMPM, Cavaleiro JAS, Lévai A, Patonay T (1998) Synthesis of 4-aryl-3-(2-chromonyl)-2pyrazolines by the 1:3-dipolar cycloaddition of 2-styrylchromones with diazomethane. J Heterocycl Chem 35:217-224

Pinto DCGA, Silva AMS, Almeida LMPM, Cavaleiro JAS (2000) A convenient synthesis of new (E)-5-hydroxy-2-styrylchromones by modifications of the Baker-Venkataraman method. New J Chem 24:85-92

Rice-Evans CA, Miller NJ, Paganga G (1996) Structure-antioxidant activity relationships of flavonoids and phenolic acids. Free Radic Biol Med 20:933-956

Rush GF, Gorski JR, Ripple MG, Sowinski J, Bugelski P, Hewitt WR (1985) Organic hydroperoxide-induced lipid peroxidation and cell death in isolated hepatocytes. Toxicol Appl Pharmacol $78: 473-483$

Sies H, Summer KH (1975) Hydorperoxide-metabolizing system in rat liver. Eur J Biochem 57:503-512

Wu TW, Zeng LH, Wu J, Fung KP (1993) Morin hydrate is a plant-derived and antioxidant-based hepatoprotector. Life Sci 53:PL213-PL218 